\title{
Subjective Cognitive Impairment in 55-65-Year-Old Adults Is Associated with Negative Affective Symptoms, Neuroticism, and Poor Quality of Life
}

\author{
Amy Jenkins ${ }^{\mathrm{a}, *}$, Jeremy J. Tree ${ }^{\mathrm{b}}$, Ian M. Thornton ${ }^{\mathrm{c}}$ and Andrea Tales ${ }^{\mathrm{a}}$ \\ ${ }^{a}$ Centre for Innovative Ageing, Swansea University, Wales, UK \\ ${ }^{\mathrm{b}}$ Department of Psychology, Swansea University, Wales, UK \\ ${ }^{\mathrm{c}}$ Department of Cognitive Science, University of Malta, Malta
}

Accepted 12 December 2018

\begin{abstract}
Although subjective cognitive impairment (SCI) is increasingly recognized clinically and in research as a risk factor for mild cognitive impairment and dementia (particularly Alzheimer's disease), it is etiologically heterogeneous and potentially treatable. Compared to mild cognitive impairment and Alzheimer's disease, SCI however remains poorly characterized with debate continuing regarding its clinical relevance. The primary aim of this study was to improve the characterization of SCI within the general public by investigating functions sometimes omitted clinically or in research, namely visual attention-related information processing speed (RT) and its intra-individual variability $\left(\mathrm{IIV}_{\mathrm{RT}}\right)$, general cognition, depression, anxiety, memory, quality of life (QOL), and neuroticism. Compared to individuals without SCI, those with SCI were more likely to reveal higher scores of anxiety, depression, and neuroticism and poorer perceived physical, psychological, and environmental QOL. Within-group analysis identified no significant relationships between any of the above variables for the non-SCI group whereas for the SCI group, poorer Cognitive Change Index scores were significantly correlated with slower $\mathrm{RT}$, raised IIV $\mathrm{RT}_{\mathrm{RT}}$, poorer memory, negative affective symptoms, higher neuroticism scores, and poorer QOL. This indicates that reports of perceived memory changes in SCI can also be associated with other characteristics, namely objectively measured detrimental change in other aspects of brain function and behavior. This outcome emphasizes the importance of a multi-function approach to characterizing and understanding SCI. Thus, although the effect of RT and $\mathrm{IIV}_{\mathrm{RT}}$ is not strong enough to differentiate SCI from non-SCI at group level, slowing and raised $\mathrm{IIV}_{\mathrm{RT}}$ do appear to characterize some people with SCI.
\end{abstract}

Keywords: Anxiety, dementia, depression, memory, neuroticism, quality of life, reaction time, subjective cognitive impairment, visual attention

\section{INTRODUCTION}

Subjective cognitive impairment (SCI) is defined clinically as perceived changes in memory and cognition that individuals report in the absence of objective

\footnotetext{
${ }^{*}$ Correspondence to: Dr. Amy Jenkins, College of Human and Health Sciences, Centre for Innovative Ageing, Haldane, Swansea University, Singleton Park, Swansea, SA2 8PP, UK. Tel.: +44 1792 60 4720; E-mail: A.Jenkins@Swansea.ac.uk.
}

evidence of abnormality [1]. SCI is increasingly recognized as a risk factor for mild cognitive impairment (MCI) and dementia (particularly Alzheimer's disease $[\mathrm{AD}]$ ) compared to demographically matched healthy adults free of SCI (hazard ratio $4.5 ; 95 \% \mathrm{CI}$ 1.9-10.3) [2,3]. Nevertheless, as in MCI, SCI appears etiologically heterogeneous. Although for some individuals, SCI may represent the outer limits of the normal aging process, or what is in fact normal aging 
for a particular individual with changes often considered to be 'senior moments' [4], a variety of risk and causal factors for SCI continue to be reported. These include age [5], low educational level [6], depression [7, 8], anxiety [9], chronic fatigue [10], whiplash injuries [11], schizophrenia [12], bipolar disorder [13], obsessive compulsive disorder [14], epilepsy [15], multiple sclerosis [16], stroke [17], fibromyalgia [18], sleep apnea [19], medication side effects [2], menopause [20], and thyroid dysfunction [21]. Such evidence indicates that some causes of SCI are potentially treatable and may not be related to neurodegenerative disease $[4,22]$ and that the factors contributing to SCI may be more varied and complex than previously envisaged. Furthermore, irrespective of etiology, SCI can detrimentally influence quality of life (QOL), self-perceived health [23, 24], perceived workplace performance and restrict social activities and mobility (e.g., driving a car) [25]. Despite such potentially detrimental associations and irrespective of etiology, SCI remains poorly characterized with respect to the integrity of a wide array of brain functions and with debate also continuing regarding its clinical, research, and everyday relevance [26-28]. It is clear therefore that further exploration to identify causality, characteristics, consequences, possible interventions, and required support [25], factors indicative of potentially reversible causes or neurodegenerative etiology, is imperative.

\section{Information processing speed and intra-individual variability}

At present, by definition, SCI is characterized in both clinical and research forums by the absence of significant deficits in objectively measured aspects of cognitive function such as memory, visuoconstructional skills, and executive function, namely those brain functions assessed by tools such as the Montreal Cognitive Assessment (MoCA) [29]. This focus on the functional integrity of a relatively narrow range of brain function in SCI means that its potential detrimental effect upon 'real life', other brain functions, and medical and psychological health may be underestimated or undetected by clinicians, researchers, and the general public [30]. Previous research has shown that $\mathrm{MCI}$, vascular cognitive impairment, and AD (all of which may reveal SCI as a prodromal stage) can be characterized by significant abnormality in some aspects of attentional function and attention-related reaction time (RT) and its intraindividual variability (IIV $\mathrm{RT}_{\mathrm{RT}}$ ) [30-42]. RT and IIV $_{\mathrm{RT}}$ are associated with brain white matter integrity [36], poorer daily activity levels and quality of life [43-49]. Therefore, one of the aims of this study is to examine such function in SCI. Evidence of changes in such function in SCI can be expected to improve our understanding of factors contributing to the signs and symptoms of SCI.

A challenge when investigating SCI and the comparison of study outcome is the associated lack of consensus related to its concept and terminology [21]. However, subjective cognitive decline (SCD), related more specifically to the neurodegenerative decline associated with $\mathrm{AD}$, is increasingly described clinically and in research [21]. SCI was examined in the present study in order to investigate the wider concept of perceived changes in a wide range of etiologies not specifically related to neurodegeneration, such as anxiety and mood and thus intervention for potentially reversible causes.

Furthermore, despite the fact that previous studies have tended to recruit people living with SCI with a formal diagnosis from memory services (i.e., received a clinical diagnosis of $\mathrm{SCI}$ ), not everyone perceiving detrimental changes in cognitive function seeks medical attention and thus formal assessment $[50,51]$. Such individuals may represent a sizeable proportion of community dwelling older adults [25, 50]. In order to redress this imbalance, SCI was investigated in those who had not been in contact with memory services. This study also extends previous work examining RT and IIV $_{\mathrm{RT}}$ in relation to perceived memory changes in older adults $[49,52,53]$.

\section{SCI and anxiety, depression, quality of life, neuroticism, and memory}

Although debate continues with respect to cause and effect, increasing evidence is indicative of links between SCI and anxiety, depression, the reporting of health problems, lower self-efficacy, less perceived control of potential difficulties in life, and higher scores on neuroticism, poorer QOL $[9,23,24,54-57$, $64,65]$, and links between anxiety, attention, and RT [25, 55, 58-63]. These factors will therefore be further investigated in this study. Furthermore, as a relationship between objectively identifiable cognitive impairment (i.e., MCI and/or $\mathrm{AD}$ ) and the personality trait neuroticism has frequently been identified in previous research (e.g., [66-69]), with some evidence that it acts as a mediating factor between memory complaints and physical and psychological health problems [54], neuroticism will 
also be included in the investigation of SCI in the present study.

\section{Study aims}

The aim of the current study was to further characterize SCI (in the general public) with respect to information processing speed (RT) and its IIV $\mathrm{RT}_{\mathrm{RT}}$, and with respect to visual and verbal memory function, general objectively measured cognitive functioning, anxiety, depression, QOL, and neuroticism. We hypothesized the following: RT will be slower and IIV $_{\mathrm{RT}}$ greater in individuals with compared to without SCI and that scores of general cognitive function, QOL, memory (visual and verbal) will be poorer, and scores of neuroticism, depression, and anxiety worse, in SCI.

\section{METHODS}

\section{Participants}

An opportunity sample methodology was used. Males $(\mathrm{N}=24)$ and females $(\mathrm{N}=75)$ aged 55-65 years were recruited from the general public living in South Wales, UK (Number of participants $[\mathrm{N}]=99$; mean $[\mathrm{M}]$ age $=60.43$ years, standard deviation $[\mathrm{SD}]=2.96)$. Inclusion criteria: general public aged 55-65, and from a self-reported perspective, in good general medical and mental health. Exclusion criteria: a clinical diagnosis of MCI or dementia (selfreported medical diagnosis), self-report of decline in cognitive ability which can be explained by a psychiatric or neurological disease, previous head injury, medical disorder, medication (prescribed and nonprescribed), or substance use. A further exclusion factor was a visit to their general practitioner (GP) or memory services about memory concerns. Participants were recruited via advertisement on social media, group email (i.e., 50+ Network), posters, etc. Older adults aged 55-65 years were recruited in order to represent the typical age-range through which SCI presents. This study was approved by Swansea University ethics review boards and written informed consent was obtained from all participants.

\section{Battery of measures}

Mean education level, ethnicity, employment status/level, and family history are presented in (Table 1). The test battery comprised: Cognitive Change Index (Self report) (CCI-S) and the Cognitive
Change Index (Informant report) (CCI-I) to measure SCI symptoms [71]; The World Health Organization Quality of Life (WHOQOL-BREF) (shortened version of the WHOQOL-100) [72]; Hospital Anxiety and Depression Scale (HADS) [73]; The Big Five Inventory (BFI) to measure neuroticism [74]; Montreal Cognitive Assessment (MoCA) [29]; The Rey Osterrieth Complex Figure (ROCF) to measure visual memory [75]; The Hopkins Verbal Learning Test (HVLT) to measure verbal memory [76]; The National Adult Reading Test (NART) to measure predicted IQ [77]; Trails A (TMT A) and Trails B (TMT B) [52]; and the adapted Multi-Item Localization task (MILO) [53].

Figure 1 is a schematic example of a trial from the tablet-based implementation of MILO which was employed in the current study [78]. The participants needed to touch each virtual pool ball from one to eight in ascending order as quickly, but as accurately as possible. The advantages of computer-based test presentation in comparison to paper-and-pencil tests include the recording of reaction times for each item, rather than basic completion overall such as that in the TMT (e.g., see [79]), and the capacity to investigate spatial patterns of search organization (e.g., see [80]). Additionally, the MILO task makes it possible to easily manipulate the sequence type (e.g., digits, letters, or both) and sequence behavior (e.g., items vanishing or remaining, sequence position remaining fixed or shuffling between responses), in order to investigate the temporal context of visual search [53]. Therefore, a task such as this could potentially be employed in a clinical situation, providing information about RT speed and variability and attention processing, and additional features of higher level, cognitive processing. For this study, a fixed sequence of the digits one to eight was used, and the display was configured so that items vanished when touched. The additional sequences (i.e., shuffling) were not used because only a simple measure of information processing time (RT) and IIV $_{\mathrm{RT}}$ that did not take too long to complete was required, thus mimicking the limited time a clinician would have to use such a test in real life.

The sample was split based on their CCI-S scores (CCI-S) (i.e., the SCI group and the non-SCI group) in order to determine any between-group differences (i.e., between SCI and non-SCI) or within-group relationships. The CCI measure has one set of cut-off values to use as a method of grouping, which are the ones used within the well-established Alzheimer's Disease Neuroimaging Initiative (ADNI) study [81]. 
Table 1

Participant characteristics in both the SCI and the non-SCI group

\begin{tabular}{|c|c|c|c|c|}
\hline & SCI & Non-SCI & $\begin{array}{l}\text { Pearson Chi Square Test } \\
\text { results of the corresponding } \\
\text { categories within the SCI } \\
\text { and non-SCI group }\end{array}$ & $\begin{array}{l}\text { Mann-Whitney Test results of } \\
\text { the corresponding categories } \\
\text { within the SCI and non-SCI } \\
\text { group }\end{array}$ \\
\hline Total N & 47 & 52 & - & - \\
\hline Age mean $(\mathrm{SD})[\mathrm{y}]$ & $60.34(2.71)$ & $60.52(3.20)$ & - & NS \\
\hline Gender N $(\%)$ & 35 (74.5) Female; 12 (25.5) Male & 40 (76.9) Female; 12 (23.1) Male & NS & - \\
\hline Years in FT Education mean (SD) & $14.26(2.96)$ & $15.15(2.97)$ & - & NS \\
\hline \multirow{3}{*}{ Ethnicity group $\mathrm{N}(\%)$} & Welsh - 31 (66) & Welsh - 35 (67.3) & NS & - \\
\hline & English $-8(17)$ & English $-6(11.5)$ & & - \\
\hline & British/other -8 (17) & British/other - 11 (21.2) & & - \\
\hline \multirow[t]{3}{*}{ Employment status N (\%) } & Retired or unemployed - 23 (49) & Retired or unemployed - 22 (42.3) & NS & - \\
\hline & $\begin{array}{l}\text { Employed or self-employed } \\
\text { (full time) }-15(32)\end{array}$ & $\begin{array}{l}\text { Employed or self-employed } \\
\text { (full time) }-18(34.63)\end{array}$ & & - \\
\hline & $\begin{array}{l}\text { Employed or self-employed } \\
\text { (part time) }-9(19.1)\end{array}$ & $\begin{array}{l}\text { Employed or self-employed } \\
\text { (part time) - } 12(23.08)\end{array}$ & & - \\
\hline \multirow[t]{3}{*}{ Employment level N (\%) } & Supervisor - 12 (25.5) & Supervisor - $11(21.2)$ & NS & - \\
\hline & Manager - 19 (40.4) & Manager - 27 (51.9) & & - \\
\hline & None - 16 (34.0) & None - 14 (26.9) & & - \\
\hline \multirow{3}{*}{$\begin{array}{l}\text { Family history of cognitive } \\
\text { impairment } \mathrm{N}(\%)\end{array}$} & Yes (maternal) - 18 (38.3) & Yes (maternal) - 20 (38.5) & NS & - \\
\hline & Yes (paternal) - 1 (2.1) & Yes (paternal) $-6(11.5)$ & & - \\
\hline & None - 28 (59.6) & None - $26(50.0)$ & & - \\
\hline CCI-S mean (SD) & $27.62(7.45)$ & $15.04(2.17)$ & - & $\begin{array}{l}\mathrm{U}=1.50(\mathrm{Z}=-8.57), p<0.001) \\
\text { Cohen's effect size: }-0.86 \text { Large }\end{array}$ \\
\hline CCI-I mean (SD) & $22.26(9.49)$ & $15.29(4.08)$ & - & $\begin{array}{l}\mathrm{U}=586.00(\mathrm{Z}=-4.49), p<0.001) \\
\text { Cohen's effect size: }-0.45 \text { Medium }\end{array}$ \\
\hline NART errors mean (SD) & $11.55(7.82)$ & $9.31(6.84)$ & - & NS \\
\hline
\end{tabular}

${ }^{*} \mathrm{NS}$, not significant. 


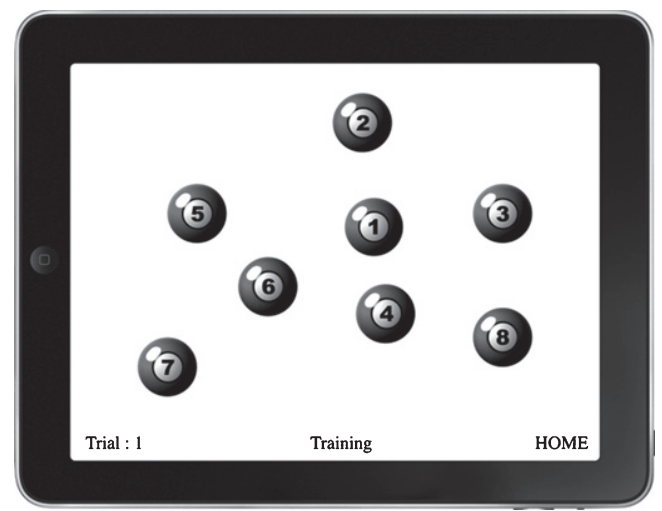

Fig. 1. The Multi-Item Localization task (MILO).

They are the only validated cut-off values, but analysis in this study using the full-scale scores yielded the same pattern of results. These cut-offs are based on the first $12 \mathrm{CCI}$ items (out of 20) which relate to perceived memory concerns. Therefore, individuals are believed to be experiencing memory concerns if they score 20 or above on the first 12 items of the CCI-S.

\section{Statistical analysis}

MILO generates data-rich results due to its multiple-trial format, thus individual RT values can be provided for each item. MILO can for instance provide data relating to the time taken to touch the first virtual pool ball (RT1), also the cumulative time it takes to touch the second pool ball (RT2) and so on, until all eight virtual pool balls have been touched (overall time is RT8). Within the current study, the measure of how quickly an individual touches all eight balls and completes the trial (RT8) was employed within the statistical analysis. As mentioned earlier, in this study, there were 30 trials in the MILO test. Therefore, the median value of RT8 was calculated for the statistical analysis of betweengroup differences and within-group correlations. The IIV $_{\mathrm{RT}}$ in relation to these 30 trials was also calculated and statistically analyzed as interquartile range (IQR).

Overall, based on Kolmogorov-Smirnov analysis the data (i.e., on the CCI, TMT A, TMT B, MILO, MoCA, HVLT, ROCF, WHOQOL-BREF, HADS, and the BFI) were not normally distributed despite score transformations, therefore non-parametric analysis was applied. This lack of normality can be typical of such studies and therefore the use of non-parametric tests is common (e.g., see $[31,32]$ ). To determine group differences (between the SCI and non-SCI group), the Mann-Whitney test was employed for continuous data and the Chi Square test was employed for categorical data. Furthermore, correlations (within-group relationships) between all test battery scores were analyzed using non-parametric Spearman's correlation coefficient. Due to the multiple comparisons being investigated in some of the correlational analyses, the Bonferroni correction method was used in order to control for the possibility of type-one errors.

\section{RESULTS}

Hypothesized a priori predictions were made and therefore one-tailed analyses were run and reported below. For completeness the analysis at a two-tailed level was also carried out, but there were only scant and minor differences between these two sets of analyses.

As can be seen in (Table 1), no significant participant characteristic group differences (i.e., age and years in education) were identified apart from for the CCI scores (which was the means by which the groups were divided [CCI-S]) [71].

Figure 2 (non-SCI group) shows the distribution of scores on the CCI-S measure from 10 (lowest possible score) to 19 (highest possible score before the SCI group cut-off score of 20). Figure 3 (SCI group) shows the distribution of scores on the CCI-S measure from 20 (lowest possible score cut-off value) to 60 (highest possible score on the CCI-S measure).

\section{Subjective cognitive impairment, information processing speed, and variability}

\section{Processing speed $(R T)$ and IIV $V_{\mathrm{RT}}$ in SCI and non-SCI}

We predicted that compared to people with no cognitive complaints, individuals with SCI (as defined by CCI scores) will have slower information processing speed (RT) with respect to TMT A, TMT $\mathrm{B}$, and MILO, and greater IIV $_{\mathrm{RT}}$ with respect to the MILO test, than individuals without SCI. Statistical analysis however failed to reveal any significant differences between groups on information processing speed with respect to TMT A, TMT B, MILO RT

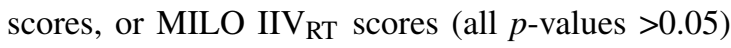
(see Supplementary Table 1 for detail). 


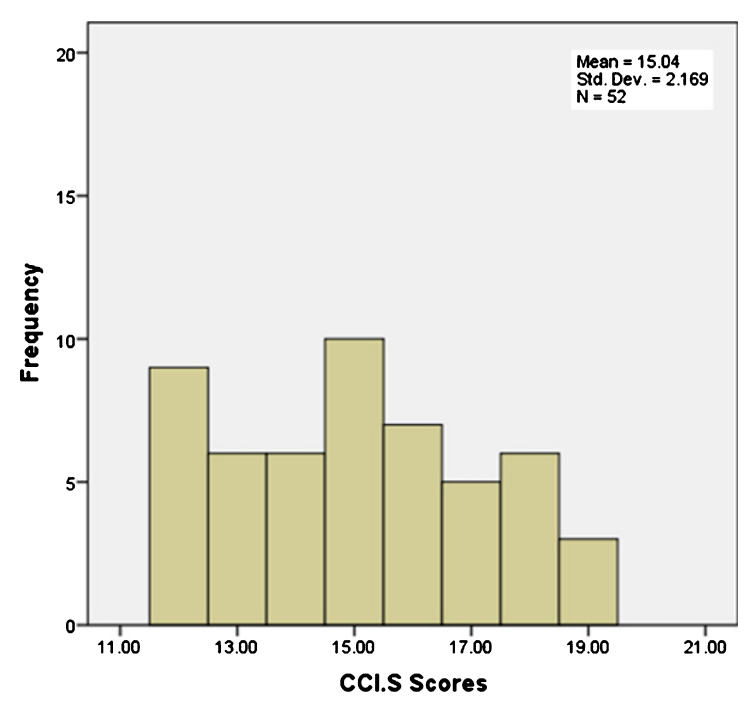

Fig. 2. Distribution of CCI-S scores within the non-SCI group.

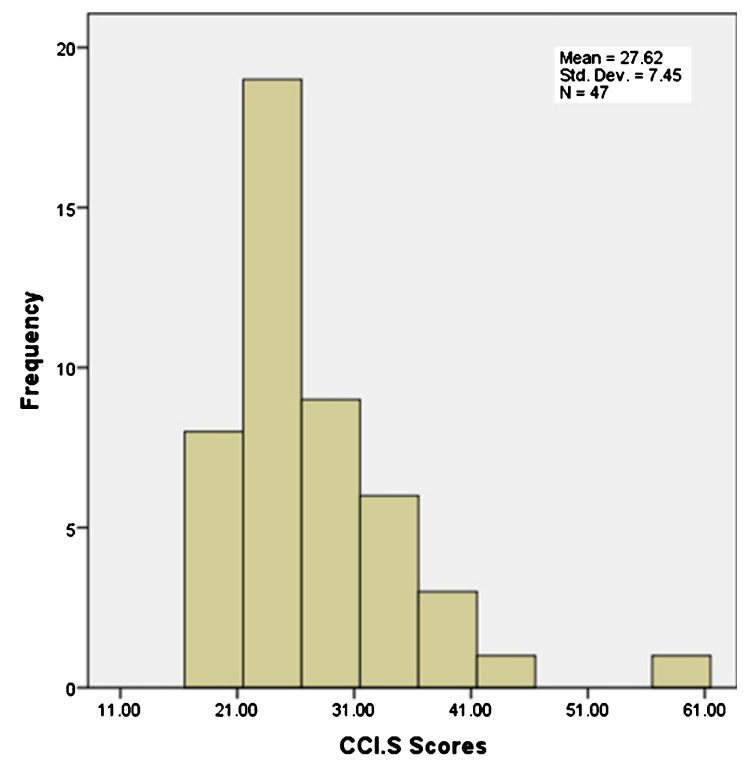

Fig. 3. Distribution of CCI-S scores within the SCI group.

\section{Within-group relationships}

There were no significant within-group correlations between CCI-S scores, RT, and IIV $\mathrm{RT}_{\mathrm{RT}}$ in the nonSCI group (all $p$ values $>0.05$ ) (see Supplementary Table 2 for details). Within the SCI group, however, the time taken to perform TMT B was significantly positively correlated to CCI-S score, i.e., the higher the CCI-S score (indicating worse perceived cognitive functioning), the slower the RT $\left(r_{\mathrm{s}}=0.35, p\right.$ (1-tailed) <0.01) (Fig. 4). Furthermore, within the SCI group, a significant positive correlation between

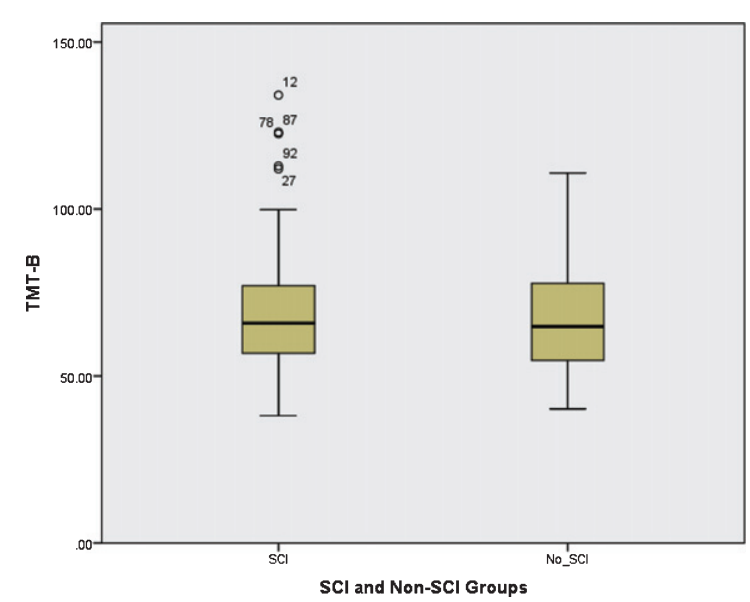

Fig. 4. Distribution of TMT B scores in the SCI and non-SCI group.

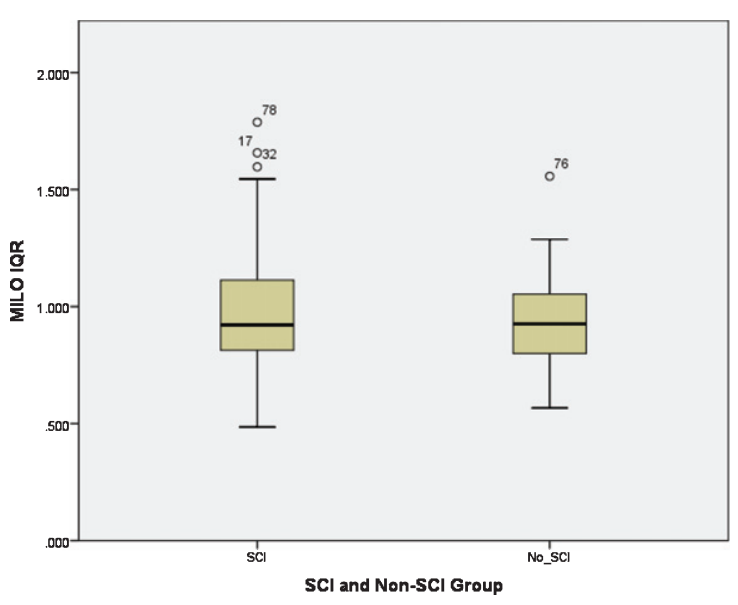

Fig. 5. Distribution of MILO IIV $\mathrm{RT}_{\mathrm{RT}}$ scores in the SCI and non-SCI group.

CCI-S scores and MILO IIV RT $_{\text {( }}=0.34, p$ (1-tailed) $<0.01$ ) was revealed (i.e., worse perceived cognitive functioning was related to greater RT variability) (Fig. 5). This remained significant after Bonferroni correction $(p=0.010)$. Figures 4 and 5 also reveal that a proportion of individuals showed disproportional slowing (RT) and greater variability (IIV $\mathrm{RT}_{\mathrm{R}}$ ) only in the SCI group. This is shown by the outliers in RT and IIV $\mathrm{RT}_{\mathrm{RT}}$, which appear in the SCI group only.

Subjective cognitive impairment, general cognitive functioning, depression, anxiety, $Q O L$, memory, and neuroticism

\section{Between-group differences}

There were no significant differences in performance on general cognitive functioning, visual 
and verbal memory, or the social relationship QOL sub-scale (all $p$ values $>0.05$ ) between the SCI and non-SCI groups (see Supplementary Table 3 for details). However, there were significant differences between these two groups regarding physical $(\mathrm{U}=709.00 \quad(\mathrm{Z}=-3.63), \quad p<0.01)$, psychological $(\mathrm{U}=728.50(\mathrm{Z}=-3.51), p<0.01)$, and environmental $(\mathrm{U}=764.50(\mathrm{Z}=-3.26), p<0.01)$ QOL (all moderate effect size). There were also significant differences on anxiety $(\mathrm{U}=670.50(\mathrm{Z}=-3.881), p<0.01$; Cohen's effect size: -0.39 moderate), depression ( $\mathrm{U}=806.00$ $(\mathrm{Z}=-2.947), p<0.01$; Cohen's effect size: -0.30 moderate), and neuroticism $(\mathrm{U}=822.00(\mathrm{Z}=-2.809)$, $p<0.01)$. Overall, the SCI group demonstrated poorer perceived physical, psychological, and environmental QOL; poorer scores on anxiety and depression; and higher levels of neuroticism respectively compared to the non-SCI group.

\section{Within-group relationships}

There were no within-group correlations in the non-SCI group between CCI-S scores and any of the variables (i.e., general cognitive functioning, memory, QOL, anxiety, depression, and neuroticism). However, in the SCI group, there were within-group correlations between CCI-S scores and performance on visual $\left(r_{\mathrm{s}}=-0.38, p\right.$ (1-tailed) $\left.<0.01\right)$ and verbal $\left(r_{\mathrm{s}}=-0.34, p\right.$ (1-tailed) <0.05) memory, physical $\left(r_{\mathrm{s}}=-0.30, p\right.$ (1-tailed) $\left.<0.05\right)$, psychological $\left(r_{\mathrm{s}}=-0.37, p\right.$ (1-tailed) <0.01), and environmental $\left(r_{\mathrm{s}}=-0.24, p\right.$ (1-tailed) <0.05) QOL, anxiety $\left(r_{\mathrm{s}}=0.39, p(1\right.$-tailed $\left.)<0.01\right)$, depression $\left(r_{\mathrm{s}}=0.45\right.$, $p$ (1-tailed) $<0.01)$, and neuroticism $\left(r_{\mathrm{s}}=0.26, p(1-\right.$ tailed) $<0.05)$. Thus, within the SCI group, poorer CCI-S scores were correlated with poorer visual and verbal memory; poorer physical, psychological, and environmental QOL; worse anxiety and depression; and higher scores on neuroticism. However, after Bonferroni correction on the QOL sub-scales, the only significant within-group correlation to remain was in relation to psychological QOL.

\section{Further analyses: Subjective cognitive impairment, slower information processing speed (RT: TMT B), greater IIV $V_{\mathrm{RT}}$, worse levels of anxiety and depression in the SCI group}

The only measure of information processing speed (RT) that was significantly correlated with CCI-S scores in the SCI group was TMT B. Also, in relation to variability, IIV $\mathrm{R}_{\mathrm{RT}}$ was significantly correlated with CCI-S scores in the SCI group. Therefore, fur- ther analyses were run to investigate whether TMT $\mathrm{B}$ and IIV $_{\mathrm{RT}}$ performance was significantly related to anxiety and depression.

Statistical analysis revealed that $\mathrm{IIV}_{\mathrm{RT}}$ was not significantly related to anxiety $\left(r_{\mathrm{s}}=0.20, p>0.05\right)$ or depression $\left(r_{\mathrm{s}}=0.04, p>0.05\right)$ scores. In relation to RT, a significant positive correlation was identified between higher scores on anxiety and poorer TMT B score (higher score, i.e., slower information processing speed) $\left(r_{\mathrm{s}}=0.34, p(1\right.$-tailed $\left.)<0.01\right)$ in those with SCI. This suggests that worse anxiety symptoms are associated with slower information processing with respect to TMT B test performance and worse scores on the CCI-S measure (i.e., slowing associated with greater perceived feelings of poor cognitive functioning). After Bonferroni correction ( $\alpha$ level $0.05 / 2=0.025)$, this remained significant $(p=0.010)$. In addition, statistical analysis revealed that there was no significant correlation between TMT B and depression $\left(r_{\mathrm{s}}=0.15, p(1\right.$-tailed $\left.)>0.05\right)$.

\section{DISCUSSION}

The aim of this study was to examine visual attention-related processing speed (RT), the intraindividual variability of reaction time $\left(\mathrm{IIV}_{\mathrm{RT}}\right)$, general cognitive functioning, memory, depression, anxiety, quality of life, and neuroticism in SCI in order to improve knowledge of its characteristics and thus of its potential signs and symptoms.

Contrary to our prediction that individuals with SCI would show greater slowing in information processing speed (RT) and greater IIV $_{\mathrm{RT}}$ variability compared to those without SCI, there was no significant difference in mean RT or IIV $_{\mathrm{RT}}$ between these groups, with respect to the TMT A and B or the MILO test. SCI per se does not therefore appear characterized by slowing and raised IIV $\mathrm{RT}_{\mathrm{RT}}$. However, within-group investigation revealed that in the SCI group only was a proportion of individuals showing disproportional slowing (RT) and greater variability $\left(\mathrm{IIV}_{\mathrm{RT}}\right)$. This is clearly demonstrated by the outliers in RT and IIV $\mathrm{RT}_{\mathrm{RT}}$, which are present only within the SCI group. For some individuals therefore, SCI is associated with slowed and/or more variable information processing speed and some individuals with SCI may therefore experience greater deficits in behaviors and activities of daily living associated with such measures (e.g., driving [25]). Furthermore, again for the SCI group only, CCI-S scores were significantly correlated with TMT B performance, not with TMT 
A, and MILO RT. Such a pattern of results indicates that although slowing (with respect to certain tasks and therefore brain processes recruited) may be related to psychological differences (e.g., anxiety), it may also represent a predictor of further decline as slowed RT and increased IIV $_{\mathrm{RT}}$ can be characteristics of MCI and AD [31-40]. However, the cross-sectional design of the current study precludes such analysis.

As predicted, levels of anxiety, depression, and neuroticism were significantly greater in the SCI compared to the non-SCI group, and QOL (all forms) was significantly poorer in the SCI group. Again, in the SCI but not the non-SCI group, CCI-S scores were significantly correlated with visual and verbal memory, anxiety, depression, physical, environmental, and psychological QOL.

This suggests that some individuals with SCI can be disproportionately slowed and variable in their responses indicating that individuals with SCI should be investigated beyond the findings of general objective outcome in currently used psychological tests. These results further highlight the need for a stratified and person-centered approach to SCI, rather than simply comparing effects at group level particularly with respect to its possibly detrimental influence upon an individuals' daily life and its potential to represent early neurodegenerative disease.

\section{Level of SCI, MoCA score}

To reiterate, the population sample in the present study was not a clinical one but represented instead those living within the community who experience poorer perceived cognition but do not approach memory services or general practitioners about it. As can be seen in (Fig. 3), the distribution of CCI-S scores in the SCI group is positively skewed, i.e., scores are loaded close to the group cut-off point (i.e., towards the non-SCI group distribution scores). This skewed distribution may represent the fact that individuals in the study tended to experience relatively low levels of cognitive decline compared to those who approach memory services or their GP and this fact could provide an explanation for the lack of significant group differences (SCI and non-SCI) in relation to TMT A, TMT B, MILO RT, and MILO IIV $\mathrm{RT}_{\text {T }}$ scores.

Importantly, the main group-differences and within-group correlations previously summarized were evident despite normal MoCA scores indicating that SCI should not be dismissed as unimportant by testing and diagnosis based solely on general cog- nitive screening tools. This is further supported by the results of Reisberg et al. [2] which revealed that 54\% of individuals with SCI declined to MCI or AD but that the average Mini-Mental State Examination [82] baseline scores for those who declined was 29 out of a maximum 30. In a clinical setting therefore, individuals with SCI, who would typically score normally on such measures, would most likely have been precluded from further investigation and follow up (see Jenkins et al. [28]).

\section{Memory}

As predicted, in the non-SCI group there were no significant correlations between CCI-S, HVLT (verbal), and ROCF (visual) scores. In the SCI group, however, both the HVLT and ROCF scores were significantly negatively correlated with CCI-S scores. The correlation between ROCF and CCI-S scores was stronger and had a greater effect size than that between HVLT and CCI-S scores. These results suggest that within the SCI group greater degrees of subjective impairment are associated with poorer visual/non-verbal memory and verbal recognition. This finding provides support for past research (i.e., see [83-85]) indicating that impairments in episodic memory are characteristic of SCI, although there are also inconsistencies in such research findings [86].

\section{Neuroticism}

Neuroticism was significantly greater in the SCI compared to the non-SCI group. Furthermore, within the SCI, but not the non-SCI group, neuroticism was significantly correlated with CCI-S score. These results are in alignment with those of Ausen et al. [66] in that a high level of neuroticism may represent a risk factor for experiencing cognitive impairment and for further decline $[54,66,69]$.

\section{Affective symptoms}

As expected, anxiety and depression (specifically sub-clinical depression, thus low mood) scores were significantly poorer for the SCI compared to the nonSCI groups. Within the SCI group only, CCI-S score (i.e., poorer SCI scores) was significantly correlated with both higher levels of anxiety and depression (sub-clinical) [8], although directional causality [25, $62,88-92]$ could not be ascertained in the current study. 


\section{Affective symptoms, $R T$ and IIV $V_{\mathrm{RT}}$}

Further analyses were run on the significant relationship found between anxiety and TMT B performance. A significant positive correlation was found between TMT B performance and anxiety, thus slower RT was associated with greater levels of anxiety indicating that processing speed on the TMT B could be associated with anxiety for those in the SCI group. No significant correlation was found between TMT B performance and sub-clinical depression scores. Despite the commonly identified co-morbid relationship between anxiety and depression [60], these results indicate that anxiety may have more impact on RT compared to depression. The identified increase in negative affective symptoms and related slowing in the SCI group supports the recommendation by Jessen et al. [21] to not dismiss such sub-threshold symptoms, to ensure they are considered when assessing for cognitive decline (specifically SCD).

\section{Quality of life}

After Bonferroni correction, only psychological QOL was significantly correlated with CCI-S scores within the SCI group, thus indicating that SCI may be particularly associated with psychological factors, again of course causality cannot be determined here $[23,24]$. Also, our finding of significantly higher levels of anxiety in the SCI group is in agreement with Strine and colleagues [93] who found that individuals with higher levels of self-reported anxiety were more likely to have poorer levels of health-related QOL [93]. Therefore, there may be an association between poor SCI, poor anxiety, and poor QOL.

Despite the inability to determine causality and loss of post correction significance, what the current study does highlight is that a characteristic of SCI is a diminished sense of psychological QOL. To conclude, a number of variables measured appeared to characterize SCI in comparison to those without SCI. At group level, individuals with SCI were more likely to have higher scores on anxiety, depression (specifically low mood), and neuroticism, together with worse perceived physical, psychological, and environmental QOL. Correlational analysis identified no significant relationships between any of the variables within the non-SCI group. However, in the SCI group, there were a number of meaningful correlations identified with CCI-S data, thus, RT (TMT B) and IIV $\mathrm{RT}_{\mathrm{R}}$ (MILO), verbal memory, non-verbal/visual memory, anxiety, depression (specifically low mood), neuroticism, and QOL.

\section{Study limitations and future research}

It is questionable whether a larger sample would have produced similar or different results. The sample size was determined based on past research studies of attention related RT tests, in MCI and AD, with typical numbers approximately between 20 and 30 participants. Since the relationship between SCI and RT (in the general public) has not been investigated using such studies and because the effects in SCI may be smaller than in MCI and AD, the number of participants in the present study was increased in each group to 50 .

The fundamental aim of this study was to highlight potential SCI characteristics in a normal population and irrespective of etiology, and its cross-sectional design thus rendered it impossible to determine causal relationships and any relationship between the findings and the development of MCI or dementia, or the successful treatment of SCI. These are areas for further and longitudinal investigation; factors beyond the scope of the present study [23, 94].

This study has provided a valuable contribution to research regarding the characterization of SCI in the general population. It is clear that despite the sample having a low level of cognitive impairment, they were still reporting poorer scores in relation to anxiety, depression, and QOL. Regardless of whether the SCI symptoms are a cause or consequence of such distress, their cognitive concerns should not be dismissed as benign. Thus, appropriate SCI management might enable potentially reversible symptoms to be treated (e.g., psychological difficulties), therefore not only possibly alleviating SCI symptoms but also decreasing the risk of further cognitive decline [60].

\section{DISCLOSURE STATEMENT}

Authors' disclosures available online (https:// www.j-alz.com/manuscript-disclosures/18-0810r3).

\section{SUPPLEMENTARY MATERIAL}

The supplementary material is available in the electronic version of this article: http://dx.doi.org/ 10.3233/JAD-180810. 


\section{REFERENCES}

[1] Stewart R (2012) Subjective cognitive impairment. Curr Opin Psychiatry 25, 445-450.

[2] Reisberg B, Shulman MB, Torossian C, Leng L, Zhu W (2010) Outcome over seven years of healthy adults with and without subjective cognitive impairment. Alzheimers Dement 6, 11-24.

[3] Fonseca JAS, Ducksbury R, Rodda J, Whitfield T, Nagaraj C, Suresh K, Stevens T, Walker Z (2015) Factors that predict cognitive decline in patients with subjective cognitive impairment. Int Psychogeriatr 27, 1671-1677.

[4] Desai AK, Schwarz L (2011) Subjective cognitive impairment: When to be concerned about 'senior moments'. Curr Psychiatry 10, 31-44.

[5] Caracciolo B, Gatz M, Xu W, Pedersen NL, Fratiglioni L (2012) Differential distribution of subjective and objective cognitive impairment in the population: A Nation-wide twin-study. J Alzheimers Dis 29, 393-403.

[6] Jonker C, Geerlings MI, Schmand B (2000) Are memory complaints predictive for dementia? A review of clinical and population-based studies. Int J Geriatr Psychiatry 15, 983-991.

[7] Grambaite R, Hessen E, Auning E, Aarsland D, Selnes P, Fladby T (2013) Correlates of subjective and mild cognitive impairment: Depressive symptoms and CSF biomarkers. Dement Geriatr Cogn Dis Extra 3, 291.

[8] Chen ST, Siddarth P, Ercoli LM, Merrill DA, Torres-Gil F, Small GW (2014) Modifiable risk factors for Alzheimer disease and subjective memory impairment across age groups. PLoS One 9, e98630.

[9] Clarnette RM, Almeida OP, Forstl H, Paton A, Martins RN (2001) Clinical characteristics of individuals with subjective memory loss in Western Australia: Results from a crosssectional survey. Int J Geriatr Psychiatry 16, 168-174.

[10] Jason LA, Torres-Harding SR, Jurgens A, Helgerson J (2004) Comparing the Fukuda et al. criteria and the Canadian case definition for chronic fatigue syndrome. J Chronic Fatigue Syndr 12, 37-52.

[11] Radanov BP, Stefano G, Schnidrig A, Augustiny KF, Sturzenegger M (1993) Cognitive functioning after common whiplash: A controlled follow-up study. Arch Neurol 50, 87-91.

[12] Homayoun S, Nadeau-Marcotte F, Luck D, Stip E (2011) Subjective and objective cognitive dysfunction in schizophrenia - is there a link? Front Psychol 2, 148.

[13] Jensen JH, Støttrup MM, Nayberg E, Knorr U, Ullum H, Purdon SE, Kessing LV, Miskowiak KW (2015) Optimising screening for cognitive dysfunction in bipolar disorder: Validation and evaluation of objective and subjective tools. J Affect Disord 187, 10-19.

[14] Moritz S, Kuelz AK, Jacobsen D, Kloss M, Fricke S (2006) Severity of subjective cognitive impairment in patients with obsessive-compulsive disorder and depression. J Anxiety Disord 20, 427-443.

[15] Grewe P, Nikstat A, Koch O, Koch-Stoecker S, Bien CG (2016) Subjective memory complaints in patients with epilepsy: The role of depression, psychological distress, and attentional functions. Epilepsy Res 127, 78-86.

[16] Julian L, Merluzzi NM, Mohr DC (2007) The relationship among depression, subjective cognitive impairment, and neuropsychological performance in multiple sclerosis. Mult Scler 13, 81-86.

[17] Tinson D J, Lincoln NB (1987) Subjective memory impairment after stroke. Disabil Rehabil 9, 6-9.
[18] Kratz AL, Schilling SG, Goesling J, Williams DA (2015) Development and initial validation of a brief self-report measure of cognitive dysfunction in fibromyalgia. J Pain 16, 527-536.

[19] Okamura T, Ura C, Miyamae F, Sugiyama M, Niikawa H, Ito K, Awata S (2016) Excessive daytime sleepiness is related to subjective memory impairment in late life: A crosssectional community-based study. Psychogeriatrics 16, 196-201.

[20] Weber MT, Mapstone M, Staskiewicz J, Maki PM (2012) Reconciling subjective memory complaints with objective memory performance in the menopausal transition. Menopause 19, 735-741.

[21] Jessen F, Amariglio RE, Van Boxtel M, Breteler M, Ceccaldi M, Chételat G, Duboisk, Carole Dufouill, Kathryn A. Ellis, van der Flier WM, Glodzik L, van Harten AC, de Leon MJ, McHugh P, Mielke MM, Molinuevo JL, Mosconi L, Osorio RS, Perrotin A, Petersen RC, Rabin RA, Rami L, Reisberg B, Rentz DM, Sachdev PS, de la Sayette V, Saykin AJ, Scheltens P, Shulman MB, Slavin MJ, Sperling RA, Stewart R, Uspenskaya O, Vellas B, Visser PJ, Wagner M (2014) A conceptual framework for research on subjective cognitive decline in preclinical Alzheimer's disease. Alzheimers Dement 10, 844-852.

[22] McIntyre RS, Soczynska JZ, Woldeyohannes HO, Alsuwaidan, MT, Cha DS, Carvalho AF, Jerrell JM, Dale RM, Gallaugher LA, Muzina DJ, Kennedy SH (2015) The impact of cognitive impairment on perceived workforce performance: Results from the International Mood Disorders Collaborative Project. Compr Psychiatry 56, 279-282.

[23] Mol M, Carpay M, Ramakers I, Rozendaal N, Verhey F, Jolles J (2007) The effect of perceived forgetfulness on quality of life in older adults; a qualitative review. Int J Geriatr Psychiatry 22, 393-400.

[24] Montejo P, Montenegro, M, Fernandez MA, Maestu F (2011) Subjective memory complaints in the elderly: Prevalence and influence of temporal orientation, depression and quality of life in a population-based study in the city of Madrid. Aging Ment Health 15, 85-97.

[25] Hill NL, Mogle JM, Munoz E, Wion R, Colancecco EM (2015) Assessment of subjective cognitive impairment among older adults. J Gerontol Nurs 41, 28-35.

[26] Fornazzari L, Fischer C, Hansen T, Ringer L (2009) Knowledge of Alzheimer's disease and subjective memory impairment in Latin American seniors in the Greater Toronto Area. Int Psychogeriatr 21, 966-969.

[27] Begum A, Morgan C, Chiu CC, Tylee A, Stewart R (2012) Subjective memory impairment in older adults: Aetiology, salience and help seeking. Int J Geriatr Psychiatry 27, 612620.

[28] Jenkins A, Tales A, Tree J, Bayer A (2015) Are we ready? The construct of subjective cognitive impairment and its utilization in clinical practice: A preliminary UK-based service evaluation. J Alzheimers Dis 48, S25-S31.

[29] Nasreddine ZS, Phillips NA, Bédirian, V, Charbonneau S, Whitehead V, Collin, I, Cummings JL, Chertkow H (2005) The Montreal Cognitive Assessment, MoCA: A brief screening tool for mild cognitive impairment. $J$ Am Geriatr Soc 53, 695-699.

[30] Tales A, Wilcock GK, Phillips JE, Bayer A (2014) Is there more to subjective cognitive impairment than meets the eye? A perspective. J Alzheimers Dis 41, 655-661.

[31] Haworth J, Phillips M, Newson M, Rogers PJ, TorrensBurton A, Tales A (2016) Measuring information processing 
speed in mild cognitive impairment: Clinical versus research dichotomy. J Alzheimers Dis 51, 263-275.

[32] Phillips M (2013) Intra-individual reaction time variability in mild cognitive impairment and Alzheimers disease: Gender, processing load and speed factors. Plos One $\mathbf{8}$, e65712.

[33] Fjell AM, Westlye LT, Amlien IK, Walhovd KB (2011) Reduced white matter integrity is related to cognitive instability. J Neurosci 31, 18060-18072.

[34] Tamnes CK, Fjell AM, Westlye LT, Østby Y, Walhovd KB (2012) Becoming consistent: Developmental reductions in intraindividual variability in reaction time are related to white matter integrity. J Neurosci 32, 972-982.

[35] Jackson JD, Balota DA, Duchek JM, Head D (2012) White matter integrity and reaction time intraindividual variability in healthy aging and early-stage Alzheimer disease. Neuropsychologia 50, 357-366.

[36] Bunce D, Anstey KJ, Christensen H, Dear K, Wen W, Sachdev P (2007) White matter hyperintensities and withinperson variability in community-dwelling adults aged 60-64 years. Neuropsychologia 45, 2009-2015.

[37] Bublak P, Redel P, Sorg C, Kurz A, Förstl H, Müller HJ, Schneider WX, Finke K (2011) Staged decline of visual processing capacity in mild cognitive impairment and Alzheimer's disease. Neurobiol Aging 32, 1219-1230.

[38] Tales A, Haworth J, Wilcock G, Newton P, Butler S (2008) Visual mismatch negativity highlights abnormal preattentive visual processing in mild cognitive impairment and Alzheimer's disease. Neuropsychologia 46, 1224-1232.

[39] Aschenbrenner AJ, Balota DA, Tse CS, Fagan AM, Holtzman DM, Benzinger TL, Morris JC (2015) Alzheimer disease biomarkers, attentional control, and semantic memory retrieval: Synergistic and mediational effects of biomarkers on a sensitive cognitive measure in nondemented older adults. Neuropsychology 29, 368-381.

[40] Levinoff EJ, Saumier D, Chertkow H (2005) Focused attention deficits in patients with Alzheimer's disease and mild cognitive impairment. Brain Cogn 57, 127-130.

[41] Tales A, Leonards U, Bompas A, Snowden RJ, Philips M, Porter G, Haworth J, Wilcock G, Bayer A (2012) Intra-individual reaction time variability in amnestic mild cognitive impairment: A precursor to dementia? $J$ Alzheimers Dis 32, 457-466.

[42] American Psychiatric Association (2013) Diagnostic and Statistical Manual of Mental Disorders: DSM-5. 5th ed. American Psychiatric Association, Washington, DC.

[43] Lin F, Chen D-G, Vance D, Mapstone M (2013) Trajectories of combined laboratory- and real world-based speed of processing in community-dwelling older adults. J Gerontol B Psychol Sci Soc Sci 68, 364-373.

[44] Batterham PJ, Bunce D, Mackinnon AJ, Christensen H (2014) Intra-individual reaction time variability and allcause mortality over 17 years: A community-based cohort study. Age Ageing 43, 84-90.

[45] Welmer AK, Rizzuto D, Qiu C, Caracciolo B, Laukka EJ (2014) Walking speed, processing speed, and dementia: A population-based longitudinal study. J Gerontol A Biol Sci Med Sci 69, 1503-1510.

[46] Anstey KJ, Dear K, Christensen H, Jorm AF (2005) Biomarkers, health, lifestyle, and demographic variables as correlates of reaction time performance in early, middle, and late adulthood. $Q J$ Exp Psychol A 58, 5-21.

[47] Eckert MA (2011) Slowing down: Age-related neurobiological predictors of processing speed. Front Neurosci $\mathbf{5}$, 25 .
[48] Hagger-Johnson GE, Shickle DA, Roberts BA, Deary IJ (2012) Neuroticism combined with slower and more variable reaction time: Synergistic risk factors for 7-year cognitive decline in females. J Gerontol B Psychol Sci Soc Sci 67, 572-581.

[49] Torrens-Burton A, Basoudan N, Bayer A, Tales A (2017) Perception and reality of cognitive function: Information processing speed, perceived memory function, and perceived task difficulty in older adults. J Alzheimers Dis 60, 1601-1609.

[50] Hurt CS, Burns A, Brown RG, Barrowclough C (2012) Why don't older adults with subjective memory complaints seek help? Int J Geriatr Psychiatry 27, 394-400.

[51] Waldorff FB, Rishoj S, Waldemar G (2008) If you don't ask (about memory), they probably won't tell. J Fam Pract 57, 41-44.

[52] Reitan R (1958) Validity of the Trail Making Test as an indicator of organic brain damage. Percept Mot Skills 8, 271-276.

[53] Thornton I, Horowitz T (2004) The multi-item localization (MILO) task: Measuring the spatiotemporal context of vision for action. Percept Psychophys 66, 38-50.

[54] Comijs HC, Deeg DJ, Dik MG, Twisk JW, Jonker C (2002) Memory complaints; the association with psycho- affective and health problems and the role of personality characteristics. A 6-year follow-up study. J Affect Disord 72, 157-167.

[55] Yochim BP, Mueller AE, Segal DL (2013) Late life anxiety is associated with decreased memory and executive functioning in community dwelling older adults. $J$ Anxiety Disord 27, 567-575.

[56] Beaudreau SA, Hara R (2008) Late-life anxiety and cognitive impairment: A review. The Am J Geriatr Psychiatry 16, 790-803.

[57] Gallacher J, Bayer A, Fish M, Pickering J, Pedro S, Dunstan F, Ebrahim S, Ben-Shlomo Y (2009) Does anxiety affect risk of dementia? Findings from the Caerphilly Prospective Study. Psychosom Med 71, 659-666.

[58] Tales A, Basoudan N (2016) Anxiety in old age and dementia - Implications for clinical and research practice. Neuropsychiatry 4, 142-148.

[59] Gale CR, Harris A, Deary IJ (2016) Reaction time and onset of psychological distress: The UK Health and Lifestyle Survey. J Epidemiol Community Health 70, 813-817.

[60] Yoo I, Woo JM, Lee SH, Fava M, Mischoulon D, Papakostas GI, Kim EJ, Chung S, Ha JH, Jeon HJ (2015) Influence of anxiety symptoms on improvement of neurocognitive functions in patients with major depressive disorder: A 12-week, multicenter, randomized trial of tianeptine versus escitalopram, the CAMPION study. J Affect Disord 185, 24-30.

[61] Roberts JL, Clare L, Woods RT (2009) Subjective memory complaints and awareness of memory functioning in mild cognitive impairment: A systematic review. Dement Geriatr Cogn Disord 28, 95-109.

[62] Diniz BS, Butters MA, Albert SM, Dew MA, Reynolds CF (2013) Late-life depression and risk of vascular dementia and Alzheimer's disease: Systematic review and metaanalysis of community-based cohort studies. Br J Psychiatry 202, 329-335.

[63] Alegret M, Rodríguez O, Espinosa A, Ortega G, Sanabria A, Valero S, Hernández I, Rosende-Roca M, Vargas L, Abdelnour C, Mauleón A, Gailhajanet A, Martín E, Tárraga L, Rentz DM, Amariglio RE, Ruíz A, Boada M (2015) Concordance between subjective and objective memory impairment in volunteer subjects. J Alzheimers Dis 48, 1109-1117. 
[64] Innes KE, Selfe TK, Khalsa DS, Kandati S (2016) Effects of meditation versus music listening on perceived stress, mood, sleep, and quality of life in adults with early memory loss: A pilot randomized controlled trial. $J$ Alzheimers Dis 52, 1277-1298.

[65] Lee H, Park S, Lim K, Park Y, Jang J (2016) Association between lifestyle and cognitive impairment among women aged 65 years and over in the Republic of Korea. Educ Gerontol 42, 198-208.

[66] Ausen B, Edman G, Almkvist O, Bogdanovic N, Ausén B (2009) Personality features in subjective cognitive impairment and mild cognitive impairment - early indicators of dementia? Dement Geriatr Cogn Disord 28, 528-535.

[67] Siegler IC, Welsh KA, Dawson DV, Fillenbaum GG, Earl NL, Kaplan EB, Clark CM (1991) Ratings of personality change in patients being evaluated for memory disorders. Alzheimer Dis Assoc Disord 5, 240-250.

[68] Crowe M, Andel R, Pedersen NL, Fratiglioni L, Gatz M (2006) Personality and risk of cognitive impairment 25 years later. Psychol Aging 21, 573-580.

[69] Balsis S, Carpenter B, Storandt M (2005) Personality change precedes clinical diagnosis of dementia of the Alzheimer type. J Gerontol B Psychol Sci Soc Sci 60, P98-P101.

[70] Ryu SY, Lee SB, Kim TW, Lee TJ (2016) Memory complaints in subjective cognitive impairment, amnestic mild cognitive impairment and mild Alzheimer's disease. Acta Neurol Belg 116, 535-541.

[71] Saykin AJ, Wishart HA, Rabin LA, Santulli RB, Flashman LA, West JD, McHugh TL, Mamourian AC (2006) Older adults with cognitive complaints show brain atrophy similar to that of amnestic MCI. Neurology 67, 834-842.

[72] (1998) Development of the World Health Organization WHOQOL-BREF quality of life assessment. The WHOQOL Group. Psychol Med 28, 551-558.

[73] Zigmond AS, Snaith RP (1983) The hospital anxiety and depression scale. Acta Psychiatr Scand 67, 361-370.

[74] John OP, Donahue EM, Kentle RL (1991) The big five inventory-versions 4a and 54. Institute of Personality and Social Research, University of California, Berkeley, CA.

[75] Spreen O, Strauss E (1991) A compendium of neuropsychological tests: Administration, norms, and commentary. Oxford University Press, New York.

[76] Brandt J (1991) The Hopkins Verbal Learning Test: Development of a new memory test with six equivalent forms. Clin Neuropsychol 5, 125-142.

[77] Nelson HE, Willison J (1991) National Adult Reading Test (NART). Nfer-Nelson Windsor.

[78] Tsui Y, Horowitz T, Thornton I (2013) Planning search for multiple targets using the iPad. Perception ECVP 42, 217 217.

[79] Dalmaijer ES, Van der Stigchel S, Nijboer TC, Cornelissen TH, Husain M (2015) CancellationTools: All-in-one software for administration and analysis of cancellation tasks. Behav Res Methods 47, 1065-1075.

[80] Woods AJ, Göksun T, Chatterjee A, Zelonis S, Mehta A, Smith SE (2013) The development of organized visual search. Acta Psychol 143, 191-199.

[81] Risacher SL, Kim S, Nho K, Foroud T, Shen L, Petersen RC, Jack CR Jr, Beckett LA, Aisen PS, Koeppe RA, Jagust WJ, Shaw LM, Trojanowski JQ, Weiner MW, Saykin AJ (2015) APOE effect on Alzheimer's disease biomarkers in older adults with significant memory concern. Alzheimers Dement 11, 1417-29.
[82] Folstein MF, Folstein SE, McHugh PR (1975) "Mini-mental state": A practical method for grading the cognitive state of patients for the clinician. J Psychiatr Res 12, 189-198.

[83] Samieri C, Proust-Lima CM, Glymour M, Okereke OI, Amariglio RE, Sperling RA, Rentz DM, Grodstein F (2014) Subjective cognitive concerns, episodic memory, and the APOE $\varepsilon 4$ allele. Alzheimers Dement 10, 752-759.e1.

[84] Striepens N, Scheef L, Wind A, Meiberth D, Popp J, Spottke A, Kölsch H, Wagner M, Jessen F (2011) Interaction effects of subjective memory impairment and ApoE4 genotype on episodic memory and hippocampal volume. Psychol Med 41, 1997-2006.

[85] Erk S, Spottke A, Meisen A, Wagner M, Walter H, Jessen F (2011) Evidence of neuronal compensation during episodic memory in subjective memory impairment. Arch Gen Psychiatry 68, 845-852.

[86] Reid LM, MacLullich AM (2006) Subjective memory complaints and cognitive impairment in older people. Dement Geriatr Cogn Disord 22, 471-486.

[87] Antikainen R, Hänninen T, Honkalampi K, Hintikka J, Koivumaa-Honkanen H, Tanskanen A, Viinamäki H (2001) A decrease in memory complaints is associated with mood improvement: A twelve-month follow up-study of depressed patients. Eur Arch Psychiatry Clin Neurosci 251, 6-11.

[88] Luck T, Riedel-Heller SG, Luppa M, Wiese B, Bachmann C, Jessen F, Bickel H, Weyerer S, Pentzek M, König HH, Prokein J, Eisele M, Wagner M, Mösch E, Werle J, Fuchs A, Brettschneider C, Scherer M, Breitner JC, Maier W (2014) A hierarchy of predictors for dementia-free survival in oldage: Results of the AgeCoDe study. Acta Psychiatr Scand 129, 63-72.

[89] Heser K, Tebarth F, Wiese B, Eisele M, Bickel H, Köhler M, Mösch E, Weyerer S, Werle J, König HH, Leicht H, Pentzek M, Fuchs A, Riedel-Heller SG, Luppa M, Prokein J, Scherer M, Maier W, Wagner M; Age CoDe Study Group (2013) Age of major depression onset, depressive symptoms, and risk for subsequent dementia: Results of the German study on Ageing, Cognition, and Dementia in Primary Care Patients (AgeCoDe). Psychol Med 43, 1597-1610.

[90] Yantis S, Nakama T (1998) Visual interactions in the path of apparent motion. Nat Neurosci 1, 508-512.

[91] Wilson E, Macleod C (2003) Contrasting two accounts of anxiety-linked attentional bias: Selective attention to varying levels of stimulus threat intensity. J Abnorm Psychol 112, 212-218.

[92] Eysenck MW (2007) Anxiety and cognitive performance: Attentional control theory. Emotion 7, 336-354.

[93] Strine T, Chapman D, Kobau R, Balluz L (2005) Associations of self- reported anxiety symptoms with health-related quality of life and health behaviors. Soc Psychiatry Psychiatr Epidemiol 40, 432-438.

[94] Wang PN, Wang SJ, Fuh JL, Teng EL, Liu CY, Lin CH, Shyu HY, Lu SR, Chen CC, Liu HC (2000) Subjective memory complaint in relation to cognitive performance and depression: A longitudinal study of a rural Chinese population. $J$ Am Geriatr Soc 48, 295-299. 